\title{
COVID-19: Impacto no Mercado de Hortaliças e Frutas
}

\author{
Fernanda de Paiva Badiz Furlaneto' ; Anelisa de Aquino Vidal Lacerda Soares'; Laura Badiz \\ Furlaneto ${ }^{2}$
}

هfernandafurlaneto@apta.sp.gov.br

1. Agência Paulista de Tecnologia dos Agronegócios (APTA), Marília/SP, Brasil. 2. Universidade de Marilia (UNIMAR), Marília/SP, Brasil.

\section{Histórico do Artigo:}

Recebido em: 25 de abril de $2020 \quad$ Aceito em: 13 de julho de $2020 \quad$ Publicado em: 31 de dezembro de 2020

Resumo: 0bjetivou-se analisar as consequências mercadológicas da quarentena no setor de hortaliças e frutas. Dada a relevância do tema COVID-19, optou-se por debater sobre alimentos seguros, efeitos do isolamento social para contenção do avanço do coronavírus sobre a cadeia produtiva de hortaliças e frutas e novas formas de comercialização. Utilizou-se para coleta dos dados a revisão integrativa da literatura e levantamento de campo. $0 \mathrm{~s}$ resultados foram apresentados na forma descritiva com ênfase na cidade de Marília, Estado de São Paulo, Brasil. Verificou-se que o consumo de hortaliças e frutas, quando corretamente manuseadas, é seguro, não apresentando riscos à saúde. Notou-se redução no consumo no atacado e varejo em torno de $32 \%$ do volume total comercializado. Novas formas de comercialização tendem a minimizar os prejuízos do setor. Os diferentes agentes da cadeia de produção sofreram impactos econômicos que comprometerão a produção à curto e médio prazo. Há necessidade de suporte de ações governamentais para evitar o desabastecimento de várias mercadorias do setor.

Palavras-chave: SARS-CoV-2, Pandemia, Horticultura, Segurança alimentar, Comercialização, Agronegócio.

\section{COVID-19: Impact on the Vegetables and fruit market}

Abstract: The objective was to analyze the market consequences of quarantine in the vegetable and fruit sector. Given the relevance of the theme COVID-19, it was decided debate about safe foods, the effects of social isolation to contain the progress of coronavirus on the vegetable and fruit production chain and new forms of commercialization. Integrative literature review and field survey were used for data collection. The results were presented in a descriptive manner with emphasis on the city of Marília, State of São Paulo, Brazil. It was found that the consumption of vegetables and fruits, when properly handled, is safe and offer no health risks. There was a reduction in consumption in wholesale and retail of around $32 \%$ of the total volume sold. New forms of commercialization tend to minimize losses in the sector. The different agents in the production chain suffered economic impacts that will compromise production in the short and medium term. There is a need to support government actions to avoid the shortage of various goods in the sector.

Keywords: SARS-CoV-2, Pandemic, Horticulture, Food security, Commercialization, Agribusiness. 


\section{COVID-19: Impacto en el Mercado de Verduras y Frutas}

Resumen: El objetivo era analizar las consecuencias del mercado de la cuarentena en el sector de frutas y verduras. Dada la relevancia del tema COVID-19, se decidió debatir sobre alimentos seguros, los efectos del aislamiento social para contener el progreso del coronavirus en la cadena de producción de vegetales y frutas y nuevas formas de comercialización. La revisión bibliográfica integral y la encuesta de campo se utilizaron para la recolección de datos. Los resultados se presentaron de manera descriptiva con énfasis en la ciudad de Marília, estado de São Paulo, Brasil. Se descubrió que el consumo de verduras y frutas, cuando se maneja adecuadamente, es seguro y no presenta riesgos para la salud. Hubo una reducción en el consumo mayorista y minorista de alrededor del 32\% del volumen total vendido. Las nuevas formas de comercialización tienden a minimizar las pérdidas en el sector. Los diferentes agentes en la cadena de producción sufrieron impactos económicos que comprometerán la producción a corto y mediano plazo. Es necesario apoyar las acciones del gobierno para evitar la escasez de diversos bienes en el sector.

Palabras clave: SARS-CoV-2, Pandemia, Horticultura, Seguridad alimentaria, Comercialización, Agronegocios.

\section{INTRODUÇÃO}

Guan et al. (2020) relataram que medidas restritivas para evitar o avanço do coronavírus da COVID-19 (Coronavirus Disease 2019) permitem diminuir a taxa de transmissão do vírus de 2,35 para 1,05, o que possibilita minimizar os efeitos da pandemia. Convém destacar que, de acordo com Doremalen et al. (2020), o SARS-Cov-2 (Severe Acute Respiratory Syndrome Coronavirus 2) é altamente contagioso por ser resistente em diversas superfícies (fômites).

Ainda, de acordo os autores, o SARS-Cov-2 sobrevive por períodos diversos em locais diferentes como aerossol (até 3 horas), cobre (até 4 horas), papelão (até 24 horas), aço inoxidável (até 2 dias) e plástico (até 3 dias). Não há estudos sobre a viabilidade desse vírus em tecidos. Todavia, trabalhos com outros patógenos apontaram que, de forma geral, os vírus podem ter sobrevida de 72 a 96 horas nos panos.

Otter et al. (2016) avaliaram o tempo de sobrevivência em superfícies do SARS-CoV e o MERS-CoV. Notou-se que na temperatura de $21^{\circ} \mathrm{C}$ o tempo de sobrevivência do vírus foi de 4 a 8 horas no alumínio, 8 horas na luva latéx e 5 dias no vidro PVC, borracha silicone, cerâmica e teflon. Observou-se, também que o coronavírus têm menor resistência em temperatura mais alta $\left(\right.$ entre $50^{\circ} \mathrm{C}$ a $\left.70^{\circ} \mathrm{C}\right)$.

Segundo a Organização Mundial da Saúde (0MS, 2020) a taxa de letalidade da COVID-19 foi estimada em torno de 3,4\%. No entanto, a variação entre países pode ser de $0 \%$ a $6,6 \%$. Essa taxa de letalidade é semelhante à da gripe espanhola (2 a 3\%) e mais elevada do que a Gripe H1N1 $(0,01$ a $0,08 \%)$. Já, a epidemia de SARS e MERS apresentaram taxas de letalidade mais elevadas de, aproximadamente, $10 \%$ e $30 \%$, respectivamente. 
0 período de incubação é de um a 14 dias, sendo a média para aparecimento de sintomas pós-contaminação de cinco a sete dias. 0 tempo médio entre os primeiros sintomas e a morte de um paciente é de 17 dias, enquanto os pacientes que se recuperam levam em média 22 dias para receber alta (GUAN et al., 2020).

Nessa acepção, no Estado de São Paulo, em 24 de março de 2020, decretou-se distanciamento social resultando na paralisação das atividades comerciais e de serviços não essenciais à população.

As atividades de beneficiamento, processamento, escoamento, distribuição e comercialização de produtos continuaram em operação em todas as cidades paulistas, no entanto, tais ações atingiram diversas regiões produtoras de frutas e hortaliças em decorrência dos impactos na comercialização das mercadorias devido à redução de consumo pela diminuição do movimento do comércio em geral.

Diante deste contexto, objetivou-se debater sobre alimentos seguros, efeitos do isolamento social para contenção do avanço do coronavírus sobre a cadeia produtiva de hortaliças e frutas, bem como expor novas formas de comercialização.

\section{MATERIAL E MÉTODOS}

Utilizou-se para coleta dos dados a revisão integrativa da literatura (BOTELH0 et al. 2011) e levantamento de campo realizado no período de 25 de março a 20 de abril de 2020, na cidade de Marília-SP. Foram aplicados um total de 45 questionários, distribuídos da seguinte forma: 5 supermercados de grande porte, 4 supermercados de pequeno porte (lojas de bairro), 2 hipermercados atacadistas, 25 consumidores, 5 produtores e 4 feirantes. No atacado e varejo foram entrevistados os responsáveis pelo "setor verde" de cada estabelecimento. Os resultados foram apresentados na forma descritiva.

Marilia localiza-se na região Centro-0este de São Paulo, a uma distância de, aproximadamente, $456 \mathrm{~km}$ da capital do Estado. A área territorial perfaz 1.170,3 km2 dos quais $42 \mathrm{~km}^{2}$ em área urbana. A taxa de urbanização é de 93\%. Em 2019, a população foi estimada em 238.882 habitantes (IBGE, 2019).

A cidade é atendida por duas importantes rodovias estaduais e uma federal: Comandante João Ribeiro de Barros (SP-294), Dona Leonor Mendes de Barros (SP-333) e a Transbrasiliana (BR-153).

0 número de estabelecimentos agropecuários corresponde a 881 unidades, totalizando uma área de 105.699 hectares. Caracteriza-se por apresentar 69\% das unidades de produção 
agrícola (UPA) com áreas de até 50 hectares. 0 valor bruto decorrente da agropecuária foi equivale a R\$ 71.296,67 mil, no ano de 2018 (IBGE, 2019)

0 número de Unidades de Produção Agropecuária (UPAs) dos municípios de Marília voltados para a produção de frutas e hortaliças corresponde a 240 estabelecimentos. 0 tamanho médio das áreas cultivadas equivale a 2,9hectares, variando de 0,8 a 9,2hectares. 0 total de área exploradas com a atividade é de 944,8 hectares. Há predomínio de mão-de-obra familiar (CDRS, 2020).

Destaca-se, ainda, que a cidade é conhecida como "Capital Nacional do Alimento" (BRASIL, 2011). 0 setor alimentício é responsável por gerar 27,5 mil empregos. Atualmente, Marília produz mais de 32 mil toneladas de alimentos por mês. Os produtos fabricados no município são comercializados em todo território nacional, bem como exportados para diversos países. As principais empresas locais são: Marilan, Dori, Bel e Yoki. Além destas, estão presentes na cidade filiais das multinacionais Nestlé e Coca-Cola.

No setor supermercadista, a região de Marília, em 2019, foi responsável por 1,7\% do faturamento do setor no Estado de São Paulo, o que equivale a aproximadamente, R\$ 1,8 bilhão. Foram gerados 9.000 empregos. Só na cidade de Marília, o setor de supermercados faturou, no ano de 2019, R\$ 531 milhões, correspondendo a 30\% da região e 0,50\% do faturamento de todo o Estado de São Paulo (APAS, 2019).

\section{RESULTADOS E DISCUSSÃ0}

\section{Covid-19 x alimento seguro}

A Autoridade Europeia de Segurança dos Alimentos (EFSA, 2020) avaliou o risco de transmissão do coronavírus por meio dos alimentos em outras epidemias causadas por vírus da mesma família e concluiu não haver risco da transmissão através dos alimentos. No entanto, deve-se considerar a transmissão através de fômites (qualquer objeto inanimado ou substância capaz de absorver, reter e transportar organismos contagiantes ou infecciosos, de um indivíduo a outro). Assim sendo, recomenda-se intensificar os cuidados com a higiene.

Ressalta-se que o coronavírus possui uma cobertura de gordura, chamada envelope, tornando-o sensível a substâncias que degradam gordura. Sendo assim, Kampf et al. (2020) relataram que a desinfecção da superfície pode ser feita com álcool (62\% a 71\%), peróxido de 
hidrogênio à $0,5 \%$ (água oxigenada) ou hipoclorito de sódio (diluir em um litro de água, uma colher de sopa de água sanitária comercial).

Salienta-se, ainda, que os vírus são estruturas muito simples e tem alta capacidade de sobrevivência podendo manter-se vivo mesmo em itens congelados, como sobre a superfície de objetos colocados no freezer ou no congelador. De acordo com Nunes (2020), em amostras descongeladas $\left(-20^{\circ} \mathrm{C}\right)$ o vírus se manteve viável, com reduzida perda de virulência.

Insta frisar que a transmissão do coronavírus depende do contato das mucosas com a secreção vinda de uma pessoa já infectada. Embora o risco de contaminação ao tocar embalagens de comidas seja baixo, há necessidade de adoção de cuidados de higiene e desinfecção de alimentos (como frutas e verduras) e embalagens (OLIVEIRA et al., 2020).

\section{Coronavírus $\mathrm{x}$ impacto da quarentena no mercado de hortaliças e frutas}

A partir do início da quarentena, observou-se entraves na comercialização de hortaliças e frutas como a redução do consumo tanto no atacado como no varejo e comprometimento do transporte dos insumos e da produção. Os caminhões de transporte relataram dificuldades para carregar/descarregar em virtude da escassez de mão-de-obra (pessoas do grupo de risco que foram afastadas do serviço) e horário reduzido de atendimento dos estabelecimentos comerciais. Alguns agricultores, também, descreveram problemas de escoamento dos produtos aos centros consumidores por falta de transporte.

Em algumas localidades notou-se impedimento do trânsito regular de caminhões que transportavam insumos. Somado a isso, algumas companhias de transportes deixaram de operar comprometendo a entrega de matéria-prima afetando a distribuição de alguns produtos essenciais. A dificuldade de obtenção de alguns insumos e a insegurança do mercado poderão postergar o investimento em novos plantios causando problemas futuros de abastecimento em determinadas regiões.

Em alguns casos os agricultores perderam parte representativa da produção (em torno de 80\%), pois dependem das compras governamentais, em especial do Programa de Aquisição de Alimentos (PAA) e Programa Nacional de Alimentação Escolar (PNAE).

Destaca-se que na primeira semana da quarentena, quando foi publicado o decreto referente ao isolamento social, os consumidores aumentaram o consumo de hortaliças e frutas nos supermercados (30\% a 40\%). Na semana seguinte, ocorreu uma reação inversa, com queda no consumo em torno de $45 \%$ em decorrência do fechamento dos restaurantes. Conjuntamente, 
ocorreu redução das compras nas centrais de abastecimento (Ceasas). Nas semanas seguintes observou-se estabilização das vendas, dentro dos índices de redução de 32\% do consumo total.

Produtores responsáveis por estabelecimentos agropecuários de grande porte econômico, que entregam diretamente sua produção em supermercados, estão conseguindo manter o escoamento de forma mais regular e com alguma estabilidade. Porém, aqueles que dependem de intermediários ou que comercializam a produção com as empresas de atacado, normalmente localizadas nas diversas centrais de abastecimento encontram dificuldades para vender a produção. Esses últimos são, em sua maioria, horticultores responsáveis por estabelecimentos agropecuários de menor porte econômico.

As cooperativas e as associações de pequenos e médios horticultores bem estruturadas estão se organizando para realizar entregas de cestas de hortaliças nos domicílios. No entanto, alguns produtos começam a faltar para completar os pedidos.

As empresas de varejo que comercializam somente alimentos estão vendendo menos do que os supermercados que oferecem produtos alimentícios, de higiene pessoal e limpeza.

Observou-se, também, redução (ou paralisação) no movimento das feiras. Dessa forma, o feirante adquire menor quantidade de hortaliças e frutas nas centrais de abastecimento.

Notou-se que a redução na comercialização de hortaliças folhosas (37\%) foi maior do que a de hortaliças não folhosas (28\%). As vendas das folhosas foram mais comprometidas pelo fechamento de parte considerável do setor de alimentação (restaurantes e lanchonetes). Salienta-se que o setor entregas de alimentos à domicílio não utilizam muitas folhosas (saladas) em decorrência da perecibilidade.

Tendo em vista a durabilidade dos produtos, há preferência de compra de hortaliças não folhosas (legumes) e frutas como tomate, abóbora, berinjela, rabanete, mandioca, cenoura, batata, maçã, manga, abacaxi, melão, caqui, maracujá, abacate e laranja.

Identificou-se, ainda, que levando em consideração as oscilações do mercado, os agricultores estão planejando mudanças na programação de plantio. Observou-se 0 cancelamento dos pedidos de mudas em torno de $20 \%$ a $30 \%$.

Outro efeito à médio prazo decorrente da pandemia poderá ser a elevação dos preços das hortaliças e frutas. No caso dos insumos que são importados, a paralisação das atividades, caso se prolongue, poderá impactar os fluxos comerciais entre diversos países. Isso, somado à expressiva alta do dólar, poderá resultar em aumento dos custos de produção.

\section{Pandemia x novos sistemas de comercialização}


Verificou-se que 90\% dos supermercados optaram pela entrega de mercadorias à domicílio. Alguns estabelecimentos isentaram a taxa de serviço e de entrega. Outros cobram a taxa de entrega que oscila entre $\mathrm{R} \$ 10,00$ e 16,00/entrega.

As empresas adotaram estratégias diferentes de venda. Alguns disponibilizaram atendimento através de sites especializados (como iFood). Dependendo da loja há limite de compra (ex.: no máximo 16 itens/entrega). Existe, também, alguns mercados que oferecem, por meio do site, somente alguns tipos de hortaliças e verduras (como brócolis, acelga, batata, tomate, banana e maçã). Adotou-se, ainda, a opção de realizar a compra e o pagamento pela internet e retirada do pedido no estabelecimento no sistema drive thru.

Relatos apontaram alguns problemas na aquisição de produtos via internet em relação ao pagamento pois, ao finalizar a compra, o cliente já realiza o pagamento. No entanto, ao receber a mercadoria no domicílio o cliente identifica a ausência de alguns itens e o valor da nota fiscal com preço diferente ao valor pago no site. Após contato com o SAC das empresas, os estabelecimentos informam que a diferença entre o valor pago e o valor da nota fiscal será restituído no cartão de crédito. No entanto, a falta dessas informações no momento da compra tem causado transtorno aos clientes.

Observou-se, também, que 40\% dos supermercados (varejo e atacado) entram em contato com o consumidor para oferecer produtos similares aos adquiridos pelo site em virtude da falta de produto no mercado físico. Essa conduta tem agradado os clientes.

Foram identificados em 4\% dos supermercados que o preço anunciado no site apresentase mais caro (em torno de $2 \%$ a 5\%) em relação ao mesmo produto adquirido pessoalmente na loja física. Os consumidores relataram, também, que usualmente compram uma quantidade inferior de produtos em relação ao que se adquire normalmente no supermercado. Tal situação pode ser justificada pelo fato da maior disponibilidade de itens na compra in locu. Deve-se considerar, também, que normalmente, costuma-se ir ao mercado com outros membros familiares que acabam sugerindo a aquisição de produtos extras à lista de compras.

Fato a ser destacado inclui, também, que na compra on line aparece a somatória do valor das mercadorias durante o processo de escolha dos produtos. Dessa forma, o cliente fica ciente do valor total a ser pago, informação esta que causa um controle mais consciente no momento da compra, facilitando dessa forma a exclusão de itens não essenciais e/ou demasiadamente repetidos.

Insta frisar que em relação ao setor de hortaliças e frutas, cada estabelecimento criou um protocolo de equivalência de produtos (item/equivalência peso). Por exemplo, no mercado l, 
o pacote de batata equivale a $600 \mathrm{~g}$ (que corresponde, aproximadamente, a X unidades de batatas). Já, no supermercado 2, cada pacote de batata corresponde a $1 \mathrm{~kg}$ do produto. Sendo assim, a compra de hortaliças e frutas na plataforma digital tornou-se complexa para clientes não habituados com os recursos digitais.

Nesse mesmo sentido, identificou-se resistência de compra em ambientes digitais por consumidores idosos (acima de 70 anos). Na prática, um outro familiar realiza a compra in locu ou pela internet visando evitar a ida do idoso ao supermercado. Mas, mesmo com as medidas restritivas, notou-se a presença de pessoas pertencentes ao grupo de risco realizando compras no mercado (sem equipamento de segurança - máscara facial), em especial, no setor "verde" (produtos hortifrutigranjeiros).

Visando atender esse público, os estabelecimentos definiram, em sua maioria, horário prioritário para atendimento (8:00 as 9:00 horas). A fim de promover uma compra mais rápida, muitos supermercados excluíram o setor de degustação de café, bem como bancos que eram distribuídos em locais estratégicos no estabelecimento e que serviam de local para encontros e conversas informais.

\section{CONCLUSÃ0}

As hortaliças e as frutas devem ser minimamente manuseadas, bem como desinfetadas antes do armazenamento e consumo. Dessa forma, há necessidade de adoção dos protocolos de higiene e distanciamento social entre os trabalhadores rurais, bem como rigorosa classificação dos produtos visando evitar a reclassificação nos entrepostos comerciais, preservando assim a saúde dos trabalhadores das centrais de abastecimento e do consumidor final em decorrência da redução do risco de contaminação dos produtos.

Dada a determinação da quarentena (suspensão das aulas presenciais) e redução representativa nas vendas de frutas e hortaliças torna-se imprescindível a distribuição dos alimentos da merenda escolar às famílias dos estudantes da rede pública de educação básica. Primordial, também, incluir horticultores com recursos mais limitados como público-alvo das políticas de transferência de renda emergencial, bem como direcionar pacote de políticas públicas voltada para repactuação de dívidas agrícolas aos agricultores mais prejudicados pela atual crise.

Preconiza-se ação coordenada entre as prefeituras e as Secretarias de Agricultura visando evitar o comprometimento do abastecimento, sendo importante estabelecer canais de 
comercialização direta entre os produtores e o consumidor final. Outra medida fundamental é a normatização das feiras livres, com regras de segurança e higiene pré-estabelecidas.

Identificou-se ser fundamental viabilizar programa especial com linhas de crédito e financiamento através de instituições financeiras para atendimento dos setores de hortaliças e frutas mais impactados pela queda no consumo.

Destaca-se que o agronegócio é campo relevante da economia pois envolve uma interrelação entre os três setores: o primário (como a agropecuária), o secundário (como as indústrias de tecnologias e transformação das matérias-primas) e o terciário (como o transporte e comercialização dos produtos advindos do campo). Sendo assim, há necessidade de apoiar os diferentes agentes econômicos das cadeias que produzem hortaliças e frutas, em decorrência dos crescentes prejuízos em suas atividades-fim.

Sem o suporte de ações governamentais, muitos agricultores (em sua maioria, produtores familiares de pequeno porte) terão que reduzir ou paralisar suas atividades, diminuindo a oferta de produtos, podendo ocorrer à curto e médio prazo desabastecimento de diversas mercadorias do setor.

\section{REFERÊNCIAS BIBLIOGRÁFICAS}

APAS. Associação Paulista de Supermercados. Supermercadistas de Marília recebem lançamento da APAS. 2019. Disponível em: https://portalapas.org.br/supermercadistas-de-marilia-recebem-lancamento-da-apas-show-2019. Acesso em: 08 abr. 2020.

BOTELHO, L. L. R. et al. 0 método da revisão integrativa nos estudos organizacionais. Gestão e sociedade, Belo Horizonte, v. 5, n. 11, p. 121-136, 2011.

BRASIL. Projeto de Lei 2229/11. Confere ao município de Marília, no Estado de São Paulo, o título de "Capital Nacional do Alimento". 2011. Disponível em: https://www.camara.leg.br. Acesso em: 10 abr. 2020.

CDRS. Coordenadoria de Desenvolvimento Rural Sustentável. Levantamento Censitário das Unidades de Produção Agropecuária do Estado de São Paulo. 2020. Disponível em: http://www.cdrs.sp.gov.br/projetolupa. Acesso em: 02 maio 2020.

DOREMALEN, N. V. et al. Aerosol and surface stability of HCoV-19 (SARS-CoV-2) compared to SARS-CoV-l. The New England Journal of Medicine, Boston, n.382, p.1564-1567, 2020.

EFSA. Autoridade Europeia de Segurança dos Alimentos. Coronavirus: no evidence that food is a source or transmission route. 2020. Disponível em: http://www.efsa.europa.eu/en/news/coronavirus-no-evidence-foodsource-or-transmission-route. Acesso em: 20 mar. 2020.

GUAN, W.J. et al. Clinical characteristics of coronavirus disease 2019 in China. The New England Journal of Medicine, Massachusetts, 2020. doi:10.1056/NEJMoa2002032.

IBGE. Instituto Brasileiro de Geografia e Estatística. Levantamento Sistemático da Produção Agrícola - LSPA. 2019. Disponível em: https://www.ibge.gov.br/estatisticas/agricultura. Acesso em: 05 abr. 2020.

KAMPF, G. et al. Persistence of coronaviruses on inanimate surfaces and their inactivation with biocidal agentes. Journal of Hospital Infection, Londres, n.104, p.246-251, 2020. 
NUNES, R. Especialista explica como higienizar alimentos durante a pandemia. 2020. Disponível em: https://www2.ufjf.br/noticias/2020/04/08/especialista-explica-como-higienizar-alimentos-durante-apandemia/. Acesso em: 12 abr. 2020.

OLIVEIRA, T. C. et al. (In)Segurança alimentar no contexto da pandemia por SARS-CoV-2. Caderno Saúde Pública, Rio de Janeiro, v.36, n.4, e00055220, 2020.

OMS. Organização Mundial da Saúde. Prioritizing diseases for research and development in emergency contexts. 2020. Disponivel em: https://www.who.int/activities/prioritizing-diseases-for-research-anddevelopment-in-emergency-contexts. Acesso em: 28 mar. 2020.

OTTER, J. A. et al. Transmission of SARS and MERS coronaviruses and influenza virus in healthcare settings: the possible role of dry surface contamination. Journal of Hospital Infection, Londres, n.92, p.235-250, 2016. 